\title{
REPRESENTAÇÕES SOCIAIS E AGRICULTURA FAMILIAR: INDÍCIOS DE PRÁTICAS AGRÍCOLAS SUSTENTÁVEIS NO VALE DO BANANAL - SALINAS, MINAS GERAIS
}

Social representations and family farming: evidence of agricultural practices in sustainable in the Bananal Valley - Salinas, Minas Gerais

\author{
Adilson José da Silva \\ Mestrando em Desenvolvimento Regional e Meio Ambiente pela Universidade Estadual de Santa Cruz \\ Salinas/MG - Brasil \\ adilsoneafsal@yahoo.com.br
}

Milton Ferreira Silva Junior

Docente do programa de Mestrado em Desenvolvimento Regional e Meio Ambiente pela Universidade Estadual de

Santa Cruz

Ilhéus/BA - Brasil

notlimf@gmail.com

Artigo recebido para publicação em 06/04/2010 e aceito para publicação em 09/11/2010

RESUMO: $\quad$ A agricultura tem mostrado através dos tempos, responsabilidade histórica na transformação dos espaços naturais, proporcionada pela crescente necessidade de produção de alimentos. A intensa discussão dos problemas ambientais da atualidade tem exigido reflexão sobre a relação homem-natureza. O presente artigo, resultado de pesquisa de mestrado no Vale do Bananal, município de Salinas, Minas Gerais, do Programa de Pós-Graduação da Universidade Estadual de Santa Cruz, traz elementos da representação social do pequeno produtor rural, sobre meio ambiente e práticas agrícolas, mediante análise de seu discurso representado na coletividade e de sua prática agrícola de base familiar. Foi utilizada a teoria das Representações Sociais com a pesquisa de campo por meio da entrevista semi-estruturada e observação direta. A análise dos dados ocorreu através do Discurso do Sujeito Coletivo. Identificou-se vários problemas ambientais como desmatamento, uso de agrotóxicos, descaracterização da mata ciliar, erosão, contaminação de rio. Pode-se inferir que embora o pequeno produtor rural do Vale do Bananal no município de Salinas, possua uma percepção naturalista do meio ambiente, há indícios de práticas de uma agricultura sustentável.

Palavras-chave: Representações Sociais. Sustentabilidade. Meio ambiente.

ABSTRACT: Agriculture has shown throughout the ages, historic responsibility in the transformation of natural spaces, brought about by the increasing need for food production. The intense discussion of the environmental problems of today has required consideration of the relationship between man and nature. This paper presents search result Masters in Banana Valley, in the municipality of Salinas, Minas Gerais, Program of Graduate Studies, State University of Santa Cruz, brings elements of the social representation of small farmers, environmental and agricultural practices, through analysis of his speech represented in the community and its family-based agricultural practices. It was to the theory of social representations with the field research through semistructured interviews and direct observation. Data analysis occurred through the Collective Subject Discourse. There were many environmental problems as deforestation, pesticide use, adulteration of riparian vegetation, erosion, contamination of river. It can be inferred that although small farmers in Banana Valley town of Salinas, has a naturalistic perception of the environment, there is evidence of sustainable agriculture practices.

Keywords: Social Representations. Sustainability. Environment. 


\section{INTRODUÇÃO}

Os reflexos da ação humana na natureza têm sido amplamente divulgados pela mídia, através de relatórios como o Painel Intergovernamental sobre Mudanças Climáticas - IPCC (Sigla em inglês), publicado em 2007 e por vários outros posteriores relatórios de estudos científicos sobre as condições da degradação do planeta. Os dados apresentados apontam para a necessidade da construção de um paradigma que se fundamente na ação ecológica em contraposição ao paradigma antropocêntrico. A mídia dá ênfase principalmente aos grandes acontecimentos como o alto índice de queimadas da floresta amazônica, o acelerado processo de degelo das calotas polares, o avanço da desertificação em vários pontos do planeta.

De um modo geral é preocupação o que aparece nos relatórios científicos. Para Kolling e Girardi (2005, p. 10) [...] "é notícia aquilo que está relacionado aos grandes desastres ambientais, aos paraísos ecológicos e aos interesses do meio de comunicação e ao capital". Não obstante, para estas autoras os meios de comunicação têm sido um aliado na educação ambiental com a divulgação de informações referente ao meio ambiente. Consideram ainda que grande parte das informações sobre meio ambiente é proveniente da mídia. Isso atribui à mídia importância na formação do saber ecológico da população.

Além da mídia a questão ambiental tem ocupado vários espaços de discussão na sociedade atual, com um forte apelo a uma prática ecológica sustentável. A educação formal tem proposto uma formação cidadã consciente da importância de uma prática ecológica no intuito de reverter à situação que se apresenta como podemos ver na Constituição Federal do Brasil de 1988, no seu Art. 255, a partir do qual cria-se um aparato jurídico para regulamentar e normatizar o uso dos recursos naturais, além de recomendar a educação ambiental, contemplada na Lei de Diretrizes e Base - LDB 9394/96, neste ainda que de forma incipiente, pois não define claramente como se dará o ensino em questão. Outro documento normativo da educação brasileira, os Parâmetros Curriculares Nacionais PCNs, também trata da educação ambiental. Neste documento é clara a orientação para fomentar mudanças de comportamento sobre o meio ambiente, no sentido de construir uma cidadania crítica, de mudança de hábitos que depredam os ambientes.

Atentas a esta discussão e ao crescente processo de degradação ambiental que ocorre no mundo todo, preocupadas com a realidade local, entidades educacionais, religiosas; organizações não governamentais (ONGs), sindicatos de trabalhadores rurais do município de Salinas, colocam na pauta de discussão local a questão ambiental, através de movimentos sociais como, organização de cursos, seminários e treinamentos de agentes multiplicadores de práticas sustentáveis na agricultura (SEBRAE, 2001).

Este artigo é resultado da pesquisa de mestrado, sobre a percepção ambiental do pequeno produtor rural do Município de Salinas no estado de Minas Gerais, especificamente dos moradores da região denominada Vale do Bananal. Para tanto, utilizou-se a teoria das representações sociais, alcançada por meio de entrevistas mediante sua saturação, alisadas através do Discurso do Sujeito Coletivo de Lefevre e Lefevre (2005), e da observação direta. No apelo de mudança de paradigma torna-se importante saber como a comunidade local percebe as questões em discussão e como se encontram os recursos naturais a sua disposição. Isto porque as ações pontuais estão diretamente interligadas com as questões de maior dimensão, pois fazem parte da mesma dinâmica global, interligada sistemicamente (CAPRA, 1996).

Analisar a questão ambiental no município de Salinas é tão importante quanto em qualquer parte do mundo, mormente por ser uma região inserida no Norte de Minas Gerais, Vale do Jequitinhonha, pertencente ao bioma Caatinga e Cerrado. Pertencendo também ao bioma Caatinga pode haver ocorrência de uma agricultura precária que se agrava conforme o índice de degradação ambiental, uma vez que neste bioma há predominância, de acordo com Mazzini (2006, p. 129), "de solos rasos e pedregoso o que torna a agricultura uma prática difícil [...]". Neste contexto a questão ambiental está fortemente relacionada às questões socioeconômicas e faz parte da discussão local um desenvolvimento sustentável que viabilize a qualidade de vida hoje e no futuro na região.

Assim como ocorre em outras localidades, Salinas apresenta problemas de ordem ambiental que chamam a atenção. Para Moreira (2005), há indícios 
de esgotamento florestal em áreas do município, em decorrência principalmente da produção de carvão vegetal com uso da mata nativa.

Nos aspectos da flora, o desmatamento para transformação de carvão tem sido aterrador na conseqüente destruição das nascentes d'àgua e redução acentuada das matas ciliares com conseqüente assoreamento dos rios e córregos secos (MOREIRA, 2005, p. 33).

A agricultura predominante praticada pelo pequeno produtor rural na região de Salinas é por definição uma agricultura familiar, de subsistência. Práticas agrícolas tradicionais na região podem se tornar mais difíceis a mitigação e agravar o universo dos problemas ambientais que afligem a sociedade local, embora seja uma produção limitada, basicamente para o sustento dos produtores e suas famílias. Prates (2003) constata que práticas de agricultura familiar culminam em resultados desastrosos para o meio ambiente.

No município de Salinas há uma predominância de propriedades deste porte. Setenta e sete por cento dos estabelecimentos têm menos de 50 hectares (SEBRAE, 2001). O município possui 2.084 propriedades rurais, com área total de 111.541 hectares (IBGE 2008).

Procurou-se superar os obstáculos epistemológicos à compreensão do rural conforme afirma Whitakher (2002) ser a contaminação do cientista pelos preconceitos. Questionar sem contestar ou se opor ao discurso do outro, mas com o respeito da existência de saberes diversos conforme a pedagogia freiriana que afirma não existir saber maior ou saber menor e sim saberes diferentes.

Conhecer o trabalho do pequeno produtor rural analisando suas representações sociais foi imprescindível na obtenção das informações que possibilitaram definir sua percepção ambiental e como ocorre sua prática. Através da análise dos dados levantados foi possível aferir as ações desses pequenos produtores rurais e nortear possíveis intervenções, considerando a importante participação de toda sociedade, por meio de subsídios necessários à ampliação e manutenção de uma agricultura que possibilite um desenvolvimento sustentável na região.
No apelo de mudança de paradigma é que foi proposto analisar a percepção ambiental do pequeno produtor rural do Vale do Bananal, município de Salinas tomando como parâmetro sua prática agrícola, levando em conta toda essa discussão mundial e local pensada articuladamente com a questão global. Portanto, como percebe e como tem ocorrido a prática agrícola do pequeno produtor rural do município de Salinas em relação ao meio ambiente consiste no problema investigado, ou seja: As representações sociais sobre meio ambiente e agricultura do pequeno produtor rural do município de Salinas apontam para práticas de agricultura sustentável?

As hipóteses levantadas foram: 1- Os costumes e necessidades dos pequenos produtores rurais não permitem perceberem os apelos de mudanças de paradigma. 2- As representações sociais dos pequenos produtores rurais envolvem valores e práticas tradicionais e sustentáveis concomitantemente.

A discussão da prática do produtor rural com relação ao meio ambiente não é recente e já foi tema analisado e discutido em outros tempos. Luzzardi (2006) comenta sobre a mudança de concepção dos produtores através de ações de intervenção nas propriedades rurais. No seu artigo "Educação Ambiental: Sustentáculo para o Desenvolvimento da Agricultura Sustentável" informa que na década de 1980 havia um questionamento por parte dos produtores e pesquisadores quanto à necessidade de quebra de paradigma.

Costa Neto e Abreu (2008) também comentam sobre os danos da prática agrícola convencional, percebidas pelos agricultores ainda na década de 1970 nos Estados Unidos da América. Perceberam a necessidade de ruptura com o modelo tradicional de prática agrícola em constatação dos danos negativos proveniente da prática utilizada e iniciou a experimentação e adoção de práticas menos agressiva ao ambiente. As mudanças foram pensadas e sugeridas pelos próprios trabalhadores em constatação dos malefícios apresentados na forma de trabalhar com os recursos naturais por meios das suas práticas cotidianas.

Mudanças de comportamento com a natureza podem ser impostas por outros contextos que não ambiental. Em Cuba o trabalho de produção de alimentos "limpos" associados à necessidade de alternativas ao 
novo modelo político-econômico pós-guerra fria, tem assegurado bons resultados para um desenvolvimento sustentável. Cuba se submeteu a transição forçada do modelo agrícola convencional para um modelo alternativo com uso de insumos naturais, pela conjuntura política que o país enfrentou com o fim da guerra fria e desintegração política da União Soviética-URSS.

Com o fim dos subsídios que Cuba recebia da antiga URSS, se viu obrigada a produzir adubos e fertilizantes. Sua produção industrial depende de matéria prima externa quase que na totalidade e com a dificuldade econômica para obtenção desta matéria prima, a alternativa foi adotar sistemas de produção orgânica. Onde havia hidroponia passou a existir "organoponia" (PAULUS, 1999).

A prática da agricultura orgânica neste país busca fortalecer um conhecimento ecológico consciente, na conservação dos recursos naturais de forma que possibilite à geração atual e futuras os meios de se reproduzir.

As mudanças são necessárias e urgentes e mecanismos surgem do pensar para a ação. É defendido por uma corrente de educadores adeptos da educação construtivista que para uma mudança de comportamento é fundamental uma educação consistente na criticidade e na participação dos envolvidos. Na educação ambiental para trabalhadores rurais é fundamental considerar o senso comum que permeia práticas do cotidiano.

Para Moscovici, citado por Allain e Camargo (2007), as representações sociais sugerem um posicionamento crítico que pode culminar em um engajamento prático. Para esse autor, as mudanças acontecem mediante criação de um movimento, que tem como proposta uma representação social alternativa. Isso ocorre, através da comunicação, implementação de estratégia de persuasão com o objetivo de influenciar a maneira de pensar e agir das pessoas.

Brandão (1995) propõe pensar a natureza na cultura, de forma incorporada pelo homem em suas relações sociais. Através da análise de citações de renomados autores, busca sustentação para a teoria "lógica da natureza" e "ética do ambiente" revestida de ideários considerados por ele místicos. Considera que é necessário alterar a essência da estrutura existente, convergindo para princípios de relacionamento de outra ordem.
Ao permitir a destruição da natureza, ao mesmo tempo em que destrói a vida, a ciência colabora com a prática social de subordinação de uns aos interesses dos outros. Porém, Marcuse (1979) considera que a tecnologia pode servir a sociedade independente das suas concepções políticas ou ideológicas. Pode ser favorável ou não. Marcuse (1979, p. 150) pondera "que a maquinaria do universo tecnológico é, 'como tal', indiferente aos fins políticos - pode revolucionar ou retardar uma sociedade." Desta forma é possível a tecnologia estar a serviço dos que a produz e a manipula, influenciada pelas relações sociais que a concebe. A sociedade atual acredita na necessária produtividade incondicional. Ainda Marcuse (1979, p.143) afirma que "Sabemos que a destruição é o preço do progresso, como a morte é o preço da vida, que a renúncia e a labuta são os requisitos para a satisfação do prazer, que os negócios devem prosseguir e que as alternativas são utópicas".

De acordo com Unger (2009) o homem tem usado a técnica para a satisfação de suas vontades estendendo o poder sobre todas as coisas numa relação de "egocentrismo" e "onipotência". Para o autor a relação estabelecida dessa forma ofusca outros modos de descoberta dos seres. Considera ainda que diante da crise ambiental em curso, importa questionar os conceitos e preconceitos, além da dinâmica do pensar. Quanto ao desenvolvimento tecnológico afirma ser possível uma convivência de uso sem a dependência exacerbada como ocorre na atualidade. Para Unger (2009, p. 161) "podemos dizer sim à utilização dos objetos técnicos e, ainda assim, manter-nos livres diante deles. Podemos 'deixar ser' estes objetos como algo que não nos envolve intimamente".

Habermas (1975) propõe a superação da dominação utilitária vertical considerada racional pela ciência, em prol de uma relação horizontal, de troca, igualdade, reciprocidade.

O quadro transcendental no qual a natureza se tornaria objeto de uma nova experiência, não seria mais a esfera de funções do agir instrumental, mas o ponto de vista de uma possível manipulação técnica cederia o seu lugar a um tratamento que, com zelo e carinho, liberasse as potências da natureza (HABERMAS, 1975, p. 307). 
Deve haver uma relação de diálogo onde homem e natureza possam estabelecer uma convivência consubstanciada em objetivos mútuos, em supressão à relação de dominação arbitrária de um lado pensante contra a subserviência pacífica da natureza. Dessa convivência pressupõe o estabelecimento da ética da reciprocidade.

Da natureza objeto, destituída de qualquer subjetividade, transformada em algo ainda desconhecido a relação homem-natureza baseada em amor, carinho, zelo é uma nova racionalidade que imprime à natureza caráter ativo dotado de sentimentos, afetos, sentidos e gestos considerados até então exclusivo das relações entre os humanos.

Grün (2009) sugere o uso da hermenêutica para uma convivência harmoniosa do ser humano com a natureza. Recomenda o engajamento com a natureza para ouvi-la e estabelecer uma relação de respeito e manutenção de sua alteridade. Para Grün (2009, p. 183) "uma compreensão hermenêutica nos leva a perceber o que poderia ser uma relação ecológica entre seres humanos e natureza. Seria uma relação na qual nós participamos na natureza e a natureza participa em nós". A sociedade por si é uma realidade organizada da natureza, porém com autonomia estabelecida através das relações entre seus elementos que pensam e age o direito entre si, ou seja, humanamente.

A pesquisa qualitativa, de acordo com Cavalcante e Nogueira (2008), atribuem ao social significados investigáveis e os discursos dos sujeitos juntamente com suas práticas tornam as matériasprimas dessa abordagem. Conforme a proposta de pesquisa realizada, de cunho qualitativo, o social com seus significados se tornam objetos passíveis de investigação. A fala ou discurso dos atores sociais e suas práticas cotidianas na agricultura caracterizam a matéria prima da investigação. Sendo assim a teoria das representações sociais, idealizada por Serge Moscovici, se apresenta adequadamente como abordagem epistemológica da pesquisa em questão.

Alvântara e Vesce (2008) consideram que a pesquisa qualitativa trabalha com análise de opiniões, representações, posicionamentos, crenças e atitudes, através de procedimentos racionais e intuitivos para melhor compreensão da complexidade dos fenômenos individuais e coletivos. Desta forma, é considerada pelos autores como altamente complexa, por lidar com interpretações e por decifrar significados. Sendo assim na metodologia adotada foram trabalhados aspectos quantitativos e qualitativos, com ênfase aos aspectos qualitativos na intenção de abordar elementos das representações sociais de meio ambiente e práticas agrícolas construídas pelos sujeitos pesquisados.

O estudo foi realizado no Vale do Bananal, com uma amostra total de 25 pequenos produtores de agricultura familiar. A coleta dos dados partiu da aplicação de uma entrevista elaborado com a finalidade de obter informações dos sujeitos, especificamente a respeito de questões relacionadas ao meio ambiente e o manejo cotidiano da propriedade rural. Foram visitadas 28 propriedades rurais, pertencentes ao Vale do Bananal. Dentre as 28 propriedades visitadas, 3 proprietários não concordaram em participar da pesquisa. A abordagem inicial junto aos entrevistados se deu no mercado municipal de Salinas com a apresentação pessoas e da pesquisa e a solicitação de colaboração voluntária. Os primeiros contatos indicaram os contatos seguintes totalizando a amostra final. O instrumento técnico metodológico utilizado foi a pesquisa de campo, por meio da entrevista semi-estruturada aplicada face a face, na propriedade rural do entrevistado e também a observação direta, realizada na mesma ocasião da entrevista, quando possível.

Para Carvalho e Nordari (2007) as subjetividades são o maior potencial das fontes orais de pesquisa, por que permitem entender valores, representações e práticas que orientam a trajetória dos atores sociais. A observação direta foi realizada no mesmo momento da entrevista quando foram realizados registros fotográficos.

Os dados obtidos foram analisados através do Discurso do Sujeito Coletivo - DSC de Lefevre e Lefevre, (2005). O DSC é uma proposta de organização e tabulação de dados qualitativos de natureza verbal. A metodologia de análise de dados, criada pelos autores citados consiste na seleção de expressões chave, idéias centrais ou ancoragens dos depoimentos coletados na pesquisas por meio de entrevista, e posteriormente articuladas para a composição de um depoimento coletivo elaborado com extratos de vários depoimentos individuais. Tal depoimento redigido na primeira pessoa do singular produz no receptor 
um efeito de opinião coletiva expressa por um único sujeito do discurso.

\section{REPRESENTAÇÃO SOCIAL, AGRICULTURA E MEIO AMBIENTE}

Idealizada pelo psicólogo Serge Moscovici, a teoria das representações sociais consiste no estudo da simbologia existente nas relações sociais. A teoria de Serge Moscovici tem no senso comum a sua matéria prima. Para Moscovici (1997, p. 9) "Os fenômenos sociais que nos permitem identificar de maneira concreta as representações e trabalhar sobre elas são, nós o sabemos, as conversações, dentro das quais se elaboram os saberes populares e o senso comum [...]". Sendo assim, as práticas e saberes dos pequenos produtores rurais do Vale do Bananal, município de Salinas, constituem representações sociais investigáveis na medida em que são objetos compartilhados na coletividade rural.

A proposta de uma percepção ambiental compatível com uma prática ecologicamente correta perpassa fundamentalmente por uma percepção que deve ser organizada a culminar em ação pelo indivíduo. $\mathrm{Na}$ concepção de Noronha (2005), através da percepção do meio ambiente é possível atribuir diversos valores e importância à natureza e a partir daí o indivíduo reconhece a necessidade do uso racional dos recursos da natureza para sua sobrevivência e de outras formas de vida que fazem parte da biodiversidade.

Barreto (2007) afirma que para a compreensão da preferência ambiental de um indivíduo é necessário o exame de vários fatores, como herança genética, processo educativo a que foi submetido, ocupação e seus arredores físicos, além da sua história cultural e a experiência de grupo. Para este autor o sentimento de apego, de pertencimento ao meio varia entre os agricultores de acordo com as condições sócioeconômicas que são postas.

O surgimento da agricultura e a domesticação de animais ocorreram entre os anos 7000 e 10000 A.C no período pré-histórico neolítico ou idade da pedra polida. A técnica inicial utilizada pelo homem para obter alimentos da terra mediante sua intervenção era limitada a utensílios fabricados de pedras polidas até chagar no formato de machados, facas e lanças.
O homem deixa de ser nômade e coletor de alimentos na natureza e passa a sedentário e agricultor, o que seria a gênese da organização do estado a partir da organização social e política do homem.

Grandes civilizações surgiram através da agricultura, desenvolvidas na maioria das vezes às margens de grandes rios. A limitação técnica submetia a produção às condições naturais, aguçando a criatividade do homem. Desde então há registros de intervenção do homem na natureza, provocando alteração no meio ambiente que variam de acordo com as condições naturais, pela necessidade crescente de aumento da produção de alimentos.

Para cada tempo sua necessidade e sua tecnologia. Assim conclui Ullrich citado por Andrioli [s.d] ao afirmar que a técnica é suficiente até o momento em que funciona. Na Idade Antiga, técnicas rudimentares como o uso da charrua, enxada foram suficientes. Em alguns locais não era necessária técnica alguma. Freitas citado por Tota e Bastos (1996) registra que os povos egípcios que cultivavam as margens férteis do rio Nilo apenas semeavam e esperavam o tempo certo da ceifa. Baixa tecnologia, pouca intervenção, impacto mínimo. Contudo, de alguma forma a transformação da natureza tem ocorrido independente da técnica usada, a partir do momento que o homem deixou de ser coletor de frutas silvestres para cultivar seu alimento.

Após longo período de letargia tecnológica do período feudal, surgem novas formas de aproveitar a terra, de aragem da terra e outros manejos que possibilitam a ampliação da produção que exige cada vez mais investimento tecnológico e ampliação da área agricultável. Do sistema auto-suficiente do feudalismo para uma produção de excedente na agricultura, culminando na modernização da agricultura com a industrialização. A indústria passa a oferecer uma variedade de insumos e máquinas para a produção ampliada.

A revolução industrial, portanto, trouxe novas técnicas e métodos de trabalhar na agricultura. A mecanização e produção de sintéticos possibilitaram a monocultura, antes tentada sem sucesso pelo desgaste excessivo da terra, conforme Barreto (2007). Com a industrialização da agricultura e a difusão do "pacote tecnológico" da revolução verde, o discurso da necessidade de alimentos em decorrência da crescente 
população justificará a adoção quase que generalizada do referido pacote tecnológico.

No debate atual há quem impute à tecnologia moderna importante implicador na degradação ambiental. Faladori e Taks (2004) consideram inadequado atribuir à tecnologia a causa principal da degradação ambiental. Em várias passagens históricas da antiguidade existem indícios de danos ambientais provenientes da ação do homem usando técnicas incipientes ou ineficientes. Para estes autores a fábula do "bom selvagem" não se sustenta e não é suficiente para inferir que as sociedades antigas devam servir de modelo para a superação dos problemas ambientais atuais.

Todavia, não ignoram a participação da tecnologia nos danos causados ao meio ambiente, ou seja, não negam a relação da tecnologia com os danos ambientais. Portanto, é necessária uma análise no tempo e o no espaço de cada contexto e verificar as relações existentes entre sociedade e natureza. A partir daí deve-se averiguar a participação de cada segmento, quando a antropologia e a sociologia têm papel fundamental nessa análise.

A tecnologia, assim como outros segmentos envolvidos na questão ambiental, necessita de estudo sistemático quanto a sua implicação na problemática ambiental. A partir daí definir sua contribuição ou não no processo de sustentabilidade na agricultura.

Gliessman (2003) considera como sustentável a agricultura que protege os recursos naturais e permite a prática de uma economia viável além de propor um aspecto social justo e aberto a toda sociedade. Para Gliessman (2003) é possível produzir mais com um enfoque agroecológico por sua característica de produção de múltiplos produtos, do que com o convencional de monocultura.

Corroborando com a concepção de Gliessman (2003), Machado (2008) considera que a agroecologia e a agrobiodiversidade podem contribuir sobremaneira para o desenvolvimento sustentável da agricultura no Brasil, na avaliação dos riscos e soluções na expansão agrícola. Para este autor a agroecologia e a agrobiodiversidade respondem às criticas de que a sustentabilidade não é possível na agricultura pela necessidade do volume de produção de alimento na garantia da segurança alimentar. Machado (2008) avalia que o conceito de agricultura sustentável é recente e responde à degradação dos recursos naturais provenientes da "agricultura moderna".

A agricultura sustentável, de acordo com Ehlers (1996), além de ser um conjunto de técnicas, é um objetivo que varia de acordo com as expectativas das mudanças, busca o equilíbrio do econômico e o ambiental, onde o agricultor imprime na sua prática agrícola fatores subjetivos e culturais que culminam numa prática socioambiental. Da discussão emerge a reivindicação por uma alternativa capaz se superar o quadro preocupante atual.

A idéia de uma 'agricultura sustentável' revela, antes de tudo, a crescente insatisfação com o status quo da agricultura moderna. Indica o desejo social de sistemas produtivos que, simultaneamente, conservem os recursos naturais e forneçam produtos mais saudáveis, sem comprometer os níveis tecnológicos já alcançados de segurança alimentar. Resulta de emergentes pressões sociais por uma agricultura que não prejudique o meio ambiente e a saúde (BEZERRA e VEIGA, 2000, p. 10).

Diante destas definições e de acordo com Carmo (1998) é possível vislumbrar a inserção da agricultura familiar na política de sustentabilidade ambiental. Para esta autora a agricultura de base familiar possui características favoráveis ao desenvolvimento de agricultura sustentável, por sua produção diversificada, com o cultivo de várias espécies, a integração da agricultura e da pecuária e outras criações com produção que ocupa espaços reduzidos.

Conforme o censo agropecuário, IBGE (2008), no Brasil foram recenseados 4.367 .902 estabelecimentos com prática de agricultura familiar que representam $84,4 \%$ do total geral de propriedades rurais, (5.175.489 estabelecimentos), mas ocupam apenas $24,3 \%$ da área dos estabelecimentos agropecuários brasileiros. Os dados apontam ainda que $75 \%$ da mão-de-obra no campo esta no segmento da agricultura familiar. É responsável pela segurança alimentar dos brasileiros abastecendo o mercado com $70 \%$ do feijão, $87 \%$ da mandioca, $58 \%$ do leite 59 dos suínos, $50 \%$ das aves, $30 \%$ dos bovinos, além 
de $21 \%$ do trigo. Com uma ocupação de apenas um quarto da área e a diversidades de produtos cultivados, a agricultura familiar responde por $38 \%$ do valor da produção total do Brasil. Apesar de cultivar uma área menor, a agricultura familiar é responsável por garantir a segurança alimentar do Brasil gerando os produtos da cesta básica consumidos pelos brasileiros.

O município de Salinas, reforçando a estatística nacional, possui uma predominância de pequenas propriedades rurais com a prática de agricultura familiar. As pequenas propriedades que desenvolvem a agricultura familiar, assim como no restante do Brasil, são caracterizadas por sua diversidade de produção considerada como ponto positivo para a sustentabilidade, conforme constatou Gomes (2004),

[...] as comunidades de Pedra Branca, Bom Retiro e Bocaina possuem tais características, com combinação de culturas intercaladas, como: videiras, arroz e feijão, porém este ponto positivo sustentável, ocorre muito em função do pequeno tamanho das propriedades [...] (GOMES, 2004, p. 09).

Com população total de 38.789 (trinta e oito mil, setecentos e oitenta e nove) habitantes (IBGE, 2009) Salinas está inserida no Norte de Minas Gerais, Vale do Jequitinhonha. O Vale do Bananal esta localizado a Leste da sede do município. A primeira comunidade que compõe o Vale do Bananal - Pedra do Peixe - dista aproximadamente $6 \mathrm{~km}$ do perímetro urbano e a última - Curralinho - $36 \mathrm{~km}$. O Vale do Bananal é divido pelo rio de mesmo nome, perenizado por seu barramento próximo da comunidade Curralinho. Está localizado a jusante deste barramento. $\mathrm{O}$ acesso à região se dá por uma rodovia sem pavimentação que acompanha o curso do rio na sua margem esquerda. As demais comunidades são: Canela D'Ema, Pavão, Curral Velho e Baixa Grande, todas visitadas na pesquisa de campo.

Pela importância dos mananciais para um ecossistema e em especial para a região de Salinas que possui má distribuição pluviométrica no decorrer do ano, o município foi investigado por amostragem, a partir da análise da região do Vale do Bananal. Além disso, esta área do município possui o maior número de ocupação das margens dos mananciais (EMATER, 2008) e maior número de produtores com a prática de agricultura familiar de acordo com Carvalho Júnior (2008), ou seja, Pequeno Produtor Rural.

Atualmente o município apresenta 2.084 (duas mil e oitenta e quatro) propriedades rurais, com área total de 111.541 ha (cento e onze mil quinhentos e quarenta e um hectares), utilizada principalmente para áreas de pastagem, 63.544 ha (sessenta e três mil quinhentas e quarenta e quatro hectares), o que demonstra que a pecuária é a principal atividade rural do município, com 49.261 (quarenta e nove mil, duzentas e sessenta e uma) cabeças (IBGE, 2007). As demais áreas estão ocupadas com lavouras temporárias, 5.468 ha (cinco mil quatrocentos e sessenta e oito hectares), lavouras permanentes, 2.067 ha (dois mil e sessenta e sete hectares), e 35.479 ha (trinta e cinco mil quatrocentos e setenta e nove hectares) de matas e florestas, e o restante com construções, benfeitorias e atividades de pequena expressão no município.

A maioria das propriedades rurais pesquisadas é de tamanho pequeno, com atividades de subsistência, e a comercialização é realizada com o excedente da produção. Foram identificadas propriedades com produção específica para a comercialização na comunidade de Canela D'Ema. Nesta comunidade há uma predominância de produção de hortaliças que são comercializadas no mercado municipal de Salinas. Porém, esta característica não desvirtua o caráter familiar de produção pela composição de todas as demais características que as qualificam como propriedades com produção de base familiar.

$\mathrm{O}$ tipo de agricultura predominante no município é a familiar, caracterizando fortemente a maioria dos produtores rurais, o que faz com que se enquadram no perfil desta categoria de produtor. Até o início da década de 1990 a população rural predominava em Salinas. O Censo demográfico do IBGE (1991) apresenta uma contagem populacional urbana de 19.543 habitantes e 31.306 habitantes na zona rural. No ano de 1996 os dados são de 17.052 habitantes urbanos e uma população rural de 17.499 habitantes. A partir de 2000 os valores invertem e a população urbana passa a predominar com 26.272 habitantes e a rural com 10.438 habitantes. De 
$62 \%$ da população rural e $28 \%$ urbana, passou para $71,5 \%$ urbana e $28,5 \%$ rural.

O fenômeno migratório no município de Salinas é, como em toda a Bacia do Jequitinhonha, uma característica marcante. O Índice de Desenvolvimento Humano (IDH) criado pela Organização das Nações Unidas (ONU) para Salinas é de 0, 699 considerado um índice médio de desenvolvimento.

O município possui como principal atividade rural a pecuária, com forte expressão para a criação de bovinos, sendo que estes estão presentes em 1.248 (mil duzentos e quarenta e oito) propriedades rurais, das 2.084 (duas mil e oitenta e quatro) existentes no município, ou seja, aproximadamente $60 \%$ (sessenta por cento), com ênfase para criação de bovinos de corte. Segundo o censo do IBGE de 2006, o município possui 54.924 (cinqüenta e quatro mil novecentas e vinte e quatro) cabeças.

A criação de suínos também está presente, principalmente nas propriedades de pequenos produtores rurais, ou seja, de agricultura familiar. A criação de aves, para postura e corte é outra atividade presente. Esta atividade é encontrada em 1.730 propriedades rurais, o que representa mais de $83 \%$ (oitenta e três por cento) das propriedades do município.

A agricultura apresenta importância significativa para a economia do município, com o cultivo principalmente de milho e feijão, para comercialização e consumo próprio. A mandioca é importante produto cultivado para comercialização in natura e fabricação de farinha, além de outros cultivos menos expressivos. Estas atividades são desenvolvidas principalmente por agricultores familiares. Assim como no cenário nacional o município de Salinas apóia-se na produção agrícola de base familiar no seu abastecimento local. Os dados do IBGE (2006) revelam que, a agricultura familiar contribui com $87 \%$ da produção nacional de mandioca, $70 \%$ de feijão, $46 \%$ do milho, $38 \%$ do café, $34 \%$ do arroz, $58 \%$ do leite. A cana-de-açúcar é cultivada por pequenos produtores, geralmente para alimentação de bovinos e fabricação de rapadura, e por produtores classificados como médio e grande, para fabricação de cachaça artesanal que também compram o excedente da produção de cana-de-açúcar dos pequenos produtores para este fim.

\section{RESULTADOS}

Os dados levantados apontam para uma consecução dos objetivos propostos. As questões elencadas no roteiro de entrevista foram facilmente entendidas pelos entrevistados de um modo geral. Quando necessário foram usadas explicações detalhadas para o perfeito entendimento. É importante destacar a receptividade da maioria dos entrevistados perante o assunto meio ambiente. Ao debaterem informalmente as questões ambientais demonstraram interesse em saber mais sobre o assunto além de preocupação com a problemática ambiental. Para os termos e definições desconhecidas era, invariavelmente, solicitado esclarecimento o que revela desejo de ampliar o saber.

Os conhecimentos sobre questões ambientais identificados nas representações do pequeno produtor rural são, predominantemente, obtidos através das informações veiculadas na televisão, apresentando-se insipiente em algumas questões tidas como comum nos meios de comunicação como um todo e em especial na televisão atualmente, como por exemplo, questões referentes ao aquecimento do planeta em decorrência do efeito estufa. É efetiva a participação do Estado na orientação de práticas sustentáveis, preeminentemente por meio da estatal Empresa de Assistências Técnica e Extensão Rural do Estado de Minas Gerais - EMATER MG e da Fundação Rural Mineira - RURALMINAS além da educação formal.

Quanto aos problemas ambientais na região, são facilmente identificáveis pelos pequenos produtores entrevistados, bem como suas causas, que são internas quando provocadas pelos moradores e externas quando por ações de pessoas estranhas, com participação marcante de fatores provenientes do meio urbano. Fica explícito na demonstração de receio - por temor ou pudor - em falar de problemas ambientais, $o$ conhecimento da ilegalidade de práticas predatórias. Este conhecimento é perceptível ao se identificar no escopo das representações sociais dos entrevistados o entendimento de hábitos, atitudes e práticas danosas ao meio ambiente.

Dentre as representações sociais identificadas, ao rio Bananal é atribuído valor econômico, cultural e de sentimento, todavia é possível identificar práticas insustentáveis ambientalmente por parte de alguns 
produtores. As conseqüências da utilização inadequada dos recursos do rio e seu entorno são sentidas diretamente pela população local que precisam de abastecimento externo de água em decorrência da péssima qualidade da água do rio Bananal para o consumo humano. Embora reconheçam sua participação na depredação do rio, a maior parcela de culpa é atribuída às causas externas.

As questões globais como, por exemplo, o aquecimento global, não são temas comuns para a maioria dos entrevistados, apesar de terem a mídia, especificamente a televisão, como principal fonte de informação e veicular atualmente aporte considerável alusivo a esta questão.

Quanto à tecnologia utilizada pelo pequeno produtor rural é basicamente rudimentar com uso de alguns equipamentos de baixa complexidade tecnológica, e que requerem dispêndio de considerável força de trabalho. Não reflete na realidade pesquisada de forma expressiva o avanço tecnológico atual de equipamentos para a produção agrícola sustentável, justificável provavelmente pela modalidade de produção de base familiar e o baixo índice de desenvolvimento econômico da região.

O preparo da terra se dá pela utilização de recursos tecnológicos rudimentares associados a alguns implementos agrícolas mecanizados, sendo estes normalmente emprestados da Associação dos Trabalhadores Rurais ou alugados de terceiros. O serviço manual ou de tração animal, principalmente para arar a terra para o plantio, contrasta com o uso de tratores que sulcam e compactam a terra com mais intensidade, até mesmo nas áreas de margens do rio, ou seja, de proteção permanente. $\mathrm{O}$ único equipamento identificado para controle de pragas, tanto para produtos naturais quanto para produtos tóxicos, foi o pulverizador manual. Nenhuma outra modalidade tecnológica para este fim foi encontrada nas propriedades pesquisadas: nem mesmo mecanismos alternativos, comuns em pequenas lavouras. Predomina o uso da força de trabalho nas várias etapas de produção, portanto.

Dentre as práticas dos pequenos produtores rurais entrevistados há uma diversidade de atividades, característica comum à produção familiar agrícola com predominância de mão-de-obra e gerenciamento da produção dos membros da família e maior incidên- cia do sexo masculino com idade acima dos 50 anos na administração das propriedades.

A prática identificada utiliza técnicas e métodos tradicionais com uso de produtos sintéticos tóxicos associados a produtos naturais e menos prejudiciais à natureza. A pecuária e a agricultura são as principais atividades desenvolvidas na região com predominância de pequenos rebanhos e pequenos cultivos diversificados. Estes pequenos cultivos, no entanto, são praticados comumente em áreas destinadas à mata ciliar, bastante descaracteriza na região pesquisada.

Os resultados apontam para uma percepção ambiental do pequeno produtor rural do município de Salinas próximo do conceito de uma percepção naturalista do meio ambiente definido por Noronha (2005), no qual o meio ambiente é representado pela natureza, a fauna, a flora e os elementos naturais, como a água, o ar, o solo. E do conceito antropocêntrico de acordo com a definição do termo por Capra (1996), onde o homem é senhor da natureza. O sentimento antropocêntrico pode ser percebido nas representações quando o pequeno produtor rural não consegue associar sua existência integrada aos elementos da natureza, mas como consumidor dos recursos naturais.

Em algumas vezes quando recorre aos recursos naturais para sua provisão, os critérios conservacionistas são preteridos, a exemplo do tratamento dado às Áreas de Proteção Permanente e a utilização de produtos sintéticos quando o nível de produção é ameaçado. As representações revelam também sensibilidade à adoção de práticas de uma agricultura sustentável. O discurso e algumas práticas alternativas, como o uso de insumos e inseticidas naturais, apontam para a sensibilidade.

A pesquisa identificou nas falas de alguns dos entrevistados mudança de comportamento relacionada à utilização de insumos orgânicos. Práticas com produtos orgânicos aparecem inseridas dentro de uma compreensão mais ampla da agricultura, relacionando-a com o meio ambiente, valores éticos e morais: "uso para proteger a vida de quem compra, de minha família e a natureza" (Ehlers, 1996, p. 11). Esta representação vai além da dualidade da agricultura familiar identificada por Andrioli [s.d] quanto à preocupação com a produção e o consumo em relação à qualidade dos alimentos. Para parte dos 
pesquisados a natureza é considerada como elemento de preocupação, juntamente com a saúde da família e consumidores dos alimentos produzidos.

Embora iniciativas positivas, motivadas por entidades e entre os moradores aconteçam, como o controle de pragas com uso de produtos naturais e o uso de adubação orgânica, ainda existe uma grande distância entre o que foi constatado e o que se pode definir como prática de uma agricultura sustentável. Os elementos das representações sociais revelaram um modelo de agricultura com predominância de práticas convencionais e algumas práticas de agricultura sustentável. A intensa discussão da sociedade atual sobre questões ambientais, com forte apelo a uma prática ecologicamente correta tem chegado ao pequeno produtor rural do Vale do Bananal, município de Salinas, portanto. Porém a percepção dos pequenos produtores entrevistados, não se materializa em ação consistente e organizada para a prática de uma agricultura sustentável de fato.

Importante destacar a presença da EMATER na região pesquisada, no fomento da sustentabilidade junto às comunidades através de cursos, palestras, dinâmicas e suporte técnico dos extensionistas nas propostas alternativas de intervenção na natureza. Faz-se necessário o envolvimento de outras entidades no fortalecimento e intensificação dessas ações.

É necessário que o poder público permaneça atuante, amplie sua ação nos segmentos de resultados positivos e busque solução para os problemas identificados, através de políticas públicas efetivas e participativas, levando em consideração as representações sociais identificadas dos atores desse ambiente.

Finalmente, vale enfatizar que a questão ambiental continua urgente e de responsabilidade de toda sociedade na elaboração de um saber capaz de agir e se organizar com responsabilidade social, econômica e ecológica.

\section{REFERÊNCIAS}

ALLAIN, J. M.; CAMARGO, B. V. O papel da mídia brasileira na construção das representações sociais de segurança alimentar. Psicologia: teoria e prática, n. 9, UFSC, p. 92-108, 2007.
ALVÂNTARA, A. M.. VESCE, G. E. P.. As representações sociais no discurso do sujeito coletivo no âmbito da pesquisa qualitativa. In: VIII CONGRESSO NACIONAL DE EDUCAÇÃO, 2008, Curitiba. Anais... Curitiba: Pontifícia Universidade Católica do Paraná. p. 2208-2220. Disponível em: <http:// www.pucpr.br/eventos/educere/educere2008/anais/ pdf/724_599.pdf >. Acesso em: 13 nov. 2009.

ANDRIOLI, A. I. Tecnologia e agricultura familiar: o movimento agroecológico como espaço de educação [s.d]. Disponível em: <http://www.anped.org.br/ reunioes/30ra/trabalhos/GT03-2873--Int.pdf $>$. Acesso em: 10 ago. 2009.

BARRETO, C. de A. Agricultura e meio ambiente: percepções e práticas de sojicultores em Rio VerdeGO. 2007. 139 f. Dissertação (Mestrado em Ciência Ambiental) - Universidade de São Paulo, São Paulo, 2007. Disponível em:

$<$ http://www.teses.usp.br/teses/disponiveis/90/90131/ tde-14082007-231915/>. Acesso em: 10 ago. 2009.

BEZERRA, M. do C. L.; VEIGA, J. E. da (Coord.), Agricultura sustentável. Brasília: Ministério do Meio Ambiente; Instituto Brasileiro do Meio Ambiente e dos Recursos Naturais Renováveis. Consórcio Museu Emílio Goeldi, 2000. Disponível em: $<\mathrm{http}: / / w w w$. camaradecultura.org/agricultura.pdf $>$. Acesso em: 10 ago. 2009.

BRANDÃO, C. R. Outros afetos, outros olhares, outras idéias, outras relações. In: NEPAM (Núcleo de Pesquisa e Estudos Ambientais). A questão ambiental: cenário de pesquisa. Campinas: UNICAMP, 1995.

BRASIL. Constituição (1988). Constituição da República Federativa do Brasil: promulgada em 05 de outubro de 1988. Brasília: Senado Federal, 1988.

Lei $n^{\circ}$ 9394, de 20 de dezembro de 1996. Disponível em:

$<$ http://portal.mec.gov.br/arquivos/pdf/ldb.pdf $>$. Acesso em: 08 out. 2008. 
Lei $n^{\circ} 11.428$, de 22 de dezembro de 2006.

Disponível em:

$<$ http://www.planalto.gov.br/ccivil 03/ ato20042006/2006/lei/111428.htm>. Acesso em: 08 out. 2008.

. Parâmetros Curriculares Nacionais: meio ambiente e saúde. Brasília: MEC/SEF, 1997.

CAPRA, F. A teia da Vida: Uma nova compreensão científica dos sistemas vivos. São Paulo: Coltrix, 1996.

CARMO, M. S. do. A produção familiar como Locus ideal da Agricultura Sustentável. Agricultura em São Paulo, v. 45, n. 1, p. 1-15, 1998. Disponível em: $<$ http://dgta.fca.unesp.br/docentes/elias/dea-pgea/ LOCUSIEA.pdf>. Acesso em: 10 out. 2009.

CARVALHO, E. B. de; NODARI, E. S. Rememorar o sertão: a percepção ambiental de lavradores no sertão paranaense. 2007. Disponível em: $<$ http:// www.cfh.ufsc.br/abho 4 sul/pdf/Ely\%20de $\% 20$ Carvalho;\%20Eunice\%20Nodari.pdf $>$. Acesso em: 12 maio 2008.

CARVALHO JÚNIOR, G. A. de. Movimento corporal dos trabalhadores na agricultura familiar no vale do bananal no municipio de Salinas - MG. 2008. Disponível em: <http://www.cnpat.embrapa.br/sbsp/ anais/Trab_Format_PDF/69.pdf $>$. Acesso em: 12 maio 2008.

COSTA NETO, C.; ABREU, M. B. Sustentabilidade agroecologia entre agricultores familiares assentados: um estudo da produção animal no assentamento fazenda são fidelis - RJ. 2008. Disponível em:

$<$ http://www.cnpat.embrapa.br/sbsp/anais/Trab_Format_PDF/144.pdf>. Acesso em: 16 abr. 2008.

EHLERS, E. Agricultura sustentável: origens e perspectiva de um novo paradigma. São Paulo: Livros da Terra, 1996. 178p. Disponível em $<$ http://hermes.ucs. br/ccea/dece/jmrocha/Resenhas/EHLERS,E.Agr.\%20 Sustent..pdf>. Acesso: 10 ago. 2009.
FALADORI, G.; TAKS, J. Um olhar antropológico sobre a questão ambiental. Revista Mana, v. 10, n. 2, out. 2004. Disponível em: <www. scielo.br/scielo.php?script=sci_arttex\&pid =S0104-93122004000200004>. Acesso em: 25 fev. 2009.

FUNDAÇÃO RURAL MINEIRA-RURALMINAS. Projeto de irrigação do vale do bananal. Salinas/MG, 2002.

GLIESSMAN, S. A agricultura pode ser sustentável. EMATER/RS, Rio Grande do Sul, 2003. Entrevista concedida a Ângela Felippi. Disponível em: <www. emater.tche.br/docs/agroeco/.../n3/03-entrevista. $\mathrm{htm}>$. Acesso em: 20 maio 2010.

GOMES, I. Sustentabilidade social e ambiental na agricultura familiar. Biologia e Ciência da Terra, v.5, n.1, p. 1-17, jul./dez. 2004.

GRÜN, M. A outridade da natureza na educação ambiental. In: CARVALHO, I. C. de M.; GRÜN, M.; TRAJBER, R. Pensar o ambiente: bases filosóficas para a educação ambiental. Brasília: Ministério da Educação, Secretaria de Educação Continuada, Alfabetização e Diversidade, UNESCO, 2009.

HABERMANS, J. Técnica e ciência enquanto ideologia. Os pensadores. São Paulo: Abril, 1975.

IBGE - Instituto Brasileiro de Geografia e Estatística. Censo agropecuário. Brasil, 2006-2008. Disponível em: $<$ http://www.ibge.gov.br/cidadesat/default2.php $>$. Acesso em: 10 set. 2009.

Censo demográfico. Brasil 1996-2007. Disponível em: $<$ http://www.ibge.gov.br/home/>. Acesso em: 10 set. 2009.

KOLLING, P., GIRARDI, I. M. T. Mídia e meio ambiente: na visão de agricultores familiares de comunidades do município de Santa Rosa/ RS. In: CONGRESSO BRASILEIRO DE CIÊNCIAS DA COMUNICAÇÃO, 2005, Rio de Janeiro, Anais... Rio de Janeiro: UERJ. 
LEFEVRE, F.; LEFEVRE, A. M. C. Depoimento e discurso: uma proposta de análise em pesquisa social. Brasília: Liber Livro, 2005.

LUZZARDI, R. do E. S. Educação ambiental: sustentáculo para o desenvolvimento da agricultura sustentável. Revista Eletrônica Mestrado Educação Ambiental, v. 17, p. 52-70, jul./dez. 2006.

MACHADO, A. T. Sustentabilidade e expansão agrícola: estratégia da agrobiodiversidade e da agroecologia no desenvolvimento sustentável da agricultura. In: BRASIL. Companhia Nacional de Abastecimento. Abastecimento e segurança alimentar: o crescimento da agricultura e a produção de alimentos no Brasil. Brasília: Conab, 2008, p. 319-325.

MARCUSE, H. A ideologia da sociedade industrial. (Trad. Giasone Rebuá). 5 ed. Rio de Janeiro: Zahar, 1979.

MAZZINI, A. L. D. de A. Dicionário educativo de termos ambientais. 3 ed. Belo Horizonte: A. L. D. Amorim Mazzini, 2006.

MOREIRA, V. A. Diagnóstico da inserção pedagógica profissional e tecnológica da Escola Agrotécnica Federal de Salinas/MG, Junto aos pequenos produtores de agricultura familiar no município de Salinas/ MG. 2005. 85f. Dissertação (Mestrado em Educação Agrícola) - Universidade Federal Rural do Rio de Janeiro, Seropédica, 2005.

MOSCOVICI, S. Prefácio. In: GUARESCHI, P.; JOVCHELOVITCH, S. (Org.), Textos em representações sociais. 3. ed. Petrópolis: Vozes, 1997. p. 7-16.

NORONHA, I. de O. Percepção e comportamento sócio-ambiental: a problemática dos resíduos sólidos urbanos. 2005. Disponível em: <http://www3. $\mathrm{mg}$.senac.br/NR/rdonlyres/ebexb6vnt62n5uln4ttjfyawt5ru7msioi34qfvtsnpgmxk75mr7lwcmo54qbewwm6v2cf5pq173he/ines.pdf $>$. Acesso em: 15 ago. 2009.
PAINEL INTERGOVERNAMENTAL SOBRE MUDANÇAS CLIMATICAS. Mudança climática 2007: a base da ciência física, Paris, fev. 2007. Disponível em: <http://www.ecolatina.com.br/pdf/IPCC-COMPLETO.pdf $>$. Acesso em: 05 mar. 2008.

PAULUS, G. Do padrão moderno à agricultura alternativa: possibilidade de transição. 1999. $172 \mathrm{f.}$. Dissertação (Mestrado em Agroecossistema) - Universidade Federal de Santa Catarina, Florianópolis, 1999. Disponível em: <http://www.agrisustentavel. com/banco/ciencia/mestrado/modsust.pdf $>$. Acesso em: 20 out. 2009.

PRATES, H. de A. Importância do trabalho de extensão rural realizado pela empresa de assistência técnica e extensão rural do estado de Minas Gerais (EMATER-MG) para a sustentabilidade ambiental no município de Salinas-MG. 2008. Monografia (Pós-Graduação em Gestão Ambiental) - Faculdades Integradas de Jacarepaguá. Jacarepaguá/RJ, 2008.

PRATES, J. A. Roteiro para elaboração do plano diretor de Salinas/MG. 2003. Monografia (Trabalho final de Graduação). Universidade Federal de Brasília, 2003.

SEBRAE/MG. Diagnóstico dos Municípios - Salinas/ MG, 2001 Disponível em: <http://www.sebraemg. com.br/arquivos/programaseprojetos/desenvolvimentolocal/diagnosticosmunicipais/salinas.pdf $>$. Acesso em: 08 ago. 2008.

TOTA, A. P.; BASTOS, P. I. de A. História Geral. São Paulo: Nova Cultura, 1996.

UNGER, N. M. Heidegger: Salvar é deixar ser. In: CARVALHO, I. C. de M.; GRÜN, M.; TRAJBER, R. (Org.), Pensar o ambiente: bases filosóficas para a educação ambiental. Brasília: Ministério da Educação, Secretaria de Educação Continuada, Alfabetização e Diversidade, UNESCO, 2009.

WHITAKER, D. C. A. Sociologia rural: questões metodológicas emergentes. São Paulo: Letras à Margem, 2002. 